\title{
Marqueurs moléculaires et génomique
}

\section{Molecular and genomic markers}

Oléagineux, Corps Gras, Lipides. Volume 7, Numéro 1, 19, Janvier - Février 2000, Filière

Auteur(s) : Régine DELOURME, Station d'amélioration des plantes, INRA, BP 29, 35653 Le Rheu Cedex, France.

Résumé : La poursuite de l'établissement de cartes génétiques est réalisée dans différentes équipes pour les principales espèces de Brassica (B. napus, B. oleracea, B. rapa, B. juncea, B. nigra) avec l'enrichissement de ces cartes en différents types de marqueurs (microsatellites, AFLP, PCR spécifiques principalement) (D. Somers, F. Dreyer, R. Raman, B. Rudolph) ou l'établissement de cartes génétiques sur de nouvelles espèces telles que Sinapis alba (M. Nelson).

\section{ARTICLE}

La poursuite de l'établissement de cartes génétiques est réalisée dans différentes équipes pour les principales espèces de Brassica (B. napus, B. oleracea, B. rapa, B. juncea, B. nigra) avec l'enrichissement de ces cartes en différents types de marqueurs (microsatellites, AFLP, PCR spécifiques principalement) (D. Somers, F. Dreyer, R. Raman, B. Rudolph) ou l'établissement de cartes génétiques sur de nouvelles espèces telles que Sinapis alba (M. Nelson).

L'étude de la relation cartes génétiques/cartes physiques est réalisée grâce au développement des banques BAC (Bacterial Artificial Chromosome) (G.J. King) et par l'utilisation de techniques d'hybridation in situ haute résolution (R.J. Snowdon).

Plusieurs présentations ont porté sur l'identification de marqueurs de différents caractères agronomiques (qualité de la graine, développement, résistance aux parasites - Phoma, Sclerotinia, altise, virus, nématode) et quelques exemples d'application en sélection, après mise au point de marqueurs PCR spécifiques, ont été présentés (P. Barret, D. Somers, J. Plieske) mais ils portaient toujours sur des caractères à déterminisme simple (composition en acides gras, résistance aux parasites).

Des moyens importants sont affectés dans différents pays au développement de nouveaux outils d'analyse du génome. La présentation générale de ces programmes a été réalisée au cours du Workshop " marqueurs moléculaires et génomique " animé par T. Osborn et I. Parkin. Ces programmes incluent l'utilisation croissante des informations acquises sur l'espèce modèle Arabidopsis (cartographie comparée, amplification de séquences colza homologues de séquences Arabidopsis), la génération de banques de mutants d'insertion, de banques d'EST (Expressed Sequence Tags), le clonage de gènes, le développement de la cartographie physique avec la production de banques BAC, le développement de l'analyse fonctionnelle du génome (séquençage de protéines, étude des interactions protéine-protéine par la technique double hybride, filtres haute densité pour analyser l'expression des gènes...). Ces programmes sont développés avec d'importants moyens au Canada (NRC-PBI et Agriculture Canada, Saskatoon) ainsi qu'en GrandeBretagne (Norwich, Wellesbourne) et par la mise en place récente de programmes nationaux tels que GABI en Allemagne et Génoplante en France. 